\title{
Management of elderly patients with acute promyelocytic leukemia: progress and problems
}

\author{
Eva Lengfelder • Wolf-Karsten Hofmann • Florian Nolte
}

Received: 22 April 2013 /Accepted: 5 May 2013 /Published online: 22 May 2013

(C) The Author(s) 2013. This article is published with open access at Springerlink.com

\begin{abstract}
Despite substantial progress in the management and outcome of acute promyelocytic leukemia (APL) during the last decades, older age remains a prominent negative prognostic factor. The improvement of long-term stabilization and cure of older APL patients is therefore a particular challenge. Data of unselected population-based studies suggest a high rate of exclusion from clinical trials in older age. The comparison of registry and study data indicates that study patients represent a positive selection. Older APL patients seem as sensitive to therapy as younger patients. With conventional therapy, based on all-trans retinoic acid (ATRA) and chemotherapy, over $50 \%$ of older APL patients can probably be cured. Special problems of advanced age are the high rate of early death before or during induction therapy and the high frequency of death in remission with negative influence on the outcome. Both may be related in part to a higher vulnerability against the common treatment with ATRA and chemotherapy. Alternative less toxic approaches including arsenic trioxide (ATO) with or without ATRA and combinations with gemtuzumab ozogamicin or with reduced chemotherapy can induce long-lasting remission in all stages of APL. Considering the high curative potential and the excellent tolerance of ATO in newly diagnosed and relapsed APL, older patients are probably a
\end{abstract}

E. Lengfelder · W.-K. Hofmann · F. Nolte

Department of Hematology and Oncology, University Hospital

Mannheim, Mannheim, Germany

E. Lengfelder $(\bowtie)$

III. Medizinische Klinik, Hämatologie und Onkologie, Universitätsmedizin Mannheim, Theodor-Kutzer-Ufer 1-3, 68167 Mannheim, Germany

e-mail: eva.lengfelder@umm.de particular target group for a chemotherapy-free approach with ATO.

Keywords Acute promyelocytic leukemia · Elderly patients $\cdot$ Incidence $\cdot$ Early death $\cdot$ Treatment $\cdot$ Prognosis

\section{Introduction}

Acute promyelocytic leukemia (APL) accounts for approximately 5-10\% of cases of acute myeloid leukemia (AML). It can be differentiated from all other forms of leukemia by its characteristic morphology (AML FAB M3/M3v) and by the diagnostic chromosomal translocation $\mathrm{t}(15 ; 17)$ with corresponding PML-RARA and RARA-PML fusion genes [1-6]. Accompanying coagulation disorders promote the appearance of life-threatening hemorrhages, which are the most frequent cause of death in the early phase of the disease [7, 8]. Approximately 20 to $30 \%$ of patients present with high white blood cell (WBC) counts associated with an inferior prognosis [9-11]. Other unfavorable prognostic factors are the expression of the CD56 antigen and the detection of FLT3 mutations [12-14]. Even in the presence of negative factors, the prognosis of APL still remains favorable in comparison to other AML subtypes if the patients receive the common treatment with all-trans retinoic acid (ATRA) and chemotherapy. The median age of patients included in larger trials is almost 40 to 45 years [15-23] (Table 1). With current treatment strategies, approximately $80 \%$ of patients with APL included in trials can be cured $[24,25]$. Older age, however, remains a striking negative prognostic factor despite improvement of prognosis over the last decades. The great majority of clinical reports on APL have focused on the progress of the younger age groups. It is 
Table 1 Overview of the rate of older APL patients included in multicenter trials with ATRA and chemotherapy

\begin{tabular}{|c|c|c|c|c|c|}
\hline Author (year) [reference] & $\begin{array}{l}\text { Number of } \\
\text { patients }\end{array}$ & $\begin{array}{l}\text { Age (years), median } \\
\text { (range) }\end{array}$ & $\geq 60$ years $(\%)$ & $\geq 70$ years $(\%)$ & $\begin{array}{l}\text { Total patients with } \\
\text { high risk (\%) }\end{array}$ \\
\hline Kanamaru (1995) [15] & 109 & $43(16-74)$ & - & 7 (>69 years) & - \\
\hline Burnett (1999) [16] & 239 & n.r. $(<14-60+)$ & 12 & 3 & 27 \\
\hline Tallman (2002) [18] & 300 & $38(1-81)$ & $10(>65$ years $)$ & - & - \\
\hline Ades $(2005)[19,33]$ & 533 & $46(32-70)$ & 24 & 6 & - \\
\hline Sanz (2010) [20] & 963 & $41(18-70+)$ & 17 & 6 & 27 \\
\hline Burnett (2012) [21] & 285 & $42(16-69)$ & 6 & 0 & 21 \\
\hline Lengfelder (2013) [22, 23] & 260 & $51(16-87)$ & 26 & 9 & 28 \\
\hline
\end{tabular}

n.r. not reported

the aim of the present review to give an overview on incidence, clinical characteristics, special problems, and treatment results of the elderly APL patients.

\section{Incidence of APL in elderly patients and inclusion in clinical trials}

It was primarily assumed that APL is less frequent in older patients. Based on data of the British Leukemia registries published in the year 2000, the incidence of APL was reported to be very low in children below the age of 10 years. Above this age limit, the incidence appeared approximately constant with increasing age [26]. Recently published results of other registries even show a significant increase of the incidence of APL in older age [27-30]. Details are shown in Table 2.

Compared to these unselected population-based studies, the rate of older patients included in clinical trials was mostly lower and ranged from 6 to $26 \%$ in patients over 60 years and from 3 to $9 \%$ at age over 70 years (Table 1 ) [15-23]. The percentage of elderly study patients assigned

Table 2 Results of population-based studies indicating higher incidence of APL and higher early death rate with increasing age

\begin{tabular}{|c|c|c|c|c|c|c|c|c|}
\hline Author (year) [reference] & Age groups (years) & No. of pts & $\begin{array}{l}\text { Incidence } \\
\text { per } 100,000\end{array}$ & Early death & $p$ value & \multicolumn{2}{|c|}{ Outcome } & $p$ value \\
\hline \multirow[t]{6}{*}{ Park (2011) [28] } & & & & $\begin{array}{l}\text { Probability } \\
\text { of ED }(\%)\end{array}$ & & \multicolumn{2}{|c|}{ Survival rate $(\%)$} & \\
\hline & & & & & & 1 year & 3 years & \\
\hline & $<35$ & 433 & 0.13 & 12.3 & $<0.001$ & 81.2 & 76.3 & $<0.001$ \\
\hline & $35-54$ & 463 & 0.26 & 16.0 & & 75.6 & 72.0 & \\
\hline & $\geq 54$ & 502 & 0.42 & 24.2 & & 53.2 & 46.4 & \\
\hline & Total & 1,400 & & & & & & \\
\hline \multirow[t]{7}{*}{ Chen (2012) [29] } & & & & $\begin{array}{l}\text { Probability } \\
\text { of ED (\%) }\end{array}$ & & \multicolumn{2}{|c|}{$\begin{array}{l}\text { Cumulative } \\
\text { relative survival }\end{array}$} & \\
\hline & & & & & & 1 year & 5 years & \\
\hline & $<20$ & 149 & 0.06 & n.r. & & 0.79 & 0.52 & \\
\hline & $20-39$ & 372 & 0.19 & n.r. & & 0.71 & 0.57 & \\
\hline & $40-59$ & 427 & 0.22 & n.r. & & 0.67 & 0.57 & \\
\hline & $\geq 60$ & 449 & 0.36 & n.r. & & 0.38 & 0.24 & \\
\hline & Total & 1,397 & & & & & & \\
\hline \multirow[t]{6}{*}{ Lehmann (2011) [27] } & & & & Rate of ED (\%) & & \multicolumn{2}{|c|}{ Survival rate $(\%)^{\mathrm{a}}$} & \\
\hline & & & & & & 1 year & 5 years & \\
\hline & $<40$ & 28 & & 19 & & 82 & 82 & \\
\hline & $40-59$ & 37 & & 16 & & 83 & 74 & \\
\hline & $\geq 60$ & 40 & & 50 & & 37 & 24 & \\
\hline & Total & 105 & & & & & & \\
\hline
\end{tabular}

n.r. not reported, pts patients, ED early death

${ }^{a}$ Approximate values extracted from survival curves 
to the high-risk group, according to the Sanz score, varied considerably and was mostly lower compared to the total study populations covering all age groups (Tables 1 and 3) [23, 31-35]. These observations suggest that a considerable rate of elderly patients is not included in clinical trials, in particular those with high-risk disease (high risk according to Sanz score: $\mathrm{WBC}$ count $>10,000 / \mu$ l, intermediate risk: WBC count $\leq 10,000 / \mu 1$ and platelet count $\leq 40,000 / \mu$ l, low risk: $\mathrm{WBC}$ count $\leq 10,000 / \mu \mathrm{l}$ and platelet count $>40,000 / \mu \mathrm{l}$ ) [9].

\section{Rate and reasons of early death in elderly APL patients}

Despite improvement of prognosis in APL by the introduction of ATRA, the early death (ED) rate remained relatively high. According to the results of the Surveillance, Epidemiology, and End Results (SEER) database from the USA, treatment advances did not improve the 30-day mortality significantly, being approximately $20 \%$ from 1977 to 2007 [36]. Other results of registries and of clinical trials showed that increasing age, worse performance status, and high WBC count have a negative impact on the ED rate [10,23, 27].

In clinical trials, the ED rate of elderly APL patients was high and ranged between 10 and $18 \%$ (Table 4) [23, 31-35]. The ED rate observed in population-based registries including unselected patients was even higher. An epidemiologic study from the USA reported an ED rate of $24 \%$ in 502 patients aged over 54 years [28]. In the Swedish Adult Acute Leukemia registry, the ED rate of all 105 registered APL patients (age, 18 to 86 years) was $29 \%$, and for patients over 60 years, it was $50 \%$ (Table 2) [27]. The German AML Cooperative Group (AMLCG) reported on 91 (30\%) registered patients aged 60 to 83 years among 305 patients with newly diagnosed APL. Of these elderly patients, $25 \%$ were not eligible for inclusion in the studies. The 30-day mortality rate of the noneligible patients was $48 \%$ [23].

Detailed analyses of the causes of death indicated that ED in younger APL patients is more frequently due to hemorrhages, whereas in older patients, the causes of ED are more variable including a high rate of death from sepsis or multiorgan failure [22, 23, 27]. The registry reports further demonstrate that age over 60 years was associated with a significantly shorter overall survival mainly influenced by the high rate of ED (Table 2) [27-30].

\section{Results of clinical studies with ATRA and chemotherapy}

Before the introduction of ATRA, 25 to $50 \%$ of patients with APL were probably cured by frontline therapy with anthracyclines and cytosine arabinoside (ara-C) [37]. Investigational studies with chemotherapy before the advent of ATRA showed that increasing cumulative anthracycline doses and the application of maintenance chemotherapy reduced the relapse rate significantly [38, 39]. Older age, microgranular variant, high leukocyte count, and severe coagulopathy were adverse prognostic factors. By combination of anthracycline-based chemotherapy with ATRA, the rate of early death and the frequency of relapses were reduced resulting in a significant improvement of longterm survival and probable cure [37]. It was the aim of subsequent studies to optimize the combination of ATRA and chemotherapy regimens, which were mostly adopted from AML treatment. These studies mainly focused on younger APL patients who had no contraindications against intensive therapy and included only smaller proportions of older patients (Table 1).

Most of the study data of the elderly patients were summarized over longer time periods and were then published in separate reports. The treatment modifications and the main results of larger studies reporting results with ATRA and chemotherapy are listed in Tables 3 and 4 . The rate of highrisk patients shows a broad range and is almost lower compared to studies including the whole APL population (Table 1). Furthermore, there is a considerable variability regarding intensity and combination of the chemotherapy

Table 3 Age distribution and treatment regimens in reports of elderly APL patients

\begin{tabular}{|c|c|c|c|c|c|c|c|}
\hline $\begin{array}{l}\text { Author (year) } \\
\text { [reference] }\end{array}$ & $\begin{array}{l}\text { Number of } \\
\text { patients }\end{array}$ & $\begin{array}{l}\text { Median age } \\
\text { (range) }\end{array}$ & $\begin{array}{l}\text { High risk } \\
(\%)\end{array}$ & $\begin{array}{l}\text { Age } \geq 70 \text { years } \\
(\%)\end{array}$ & Induction regimen & $\begin{array}{l}\text { Consolidation } \\
\text { cycles }\end{array}$ & Maintenance \\
\hline Mandelli (2005) [31] & 134 & $66(60-75)$ & - & 14 & ATRA + Ida & $1-3$ & Yes \\
\hline Sanz (2004) [32] & 104 & $68(60-83)$ & 20 & 33 & ATRA + Ida & 3 & Yes \\
\hline Ades (2005) [33] & 129 & $66(62-70)$ & - & 0 & $\mathrm{ATRA}+\mathrm{AD}$ & $1-2$ & Yes \\
\hline Lataglia (2010) [34] & 60 & $66(60-73)$ & 14 & - & ATRA + Ida & 1 & Yes \\
\hline Ono (2011) [35] & 46 & $63(60-70)$ & 20 & 0 & ATRA + Ida + Ara-C & 3 & Yes \\
\hline Lengfelder (2013) [23] & 56 & $67(60-83)$ & 32 & 32 & ATRA + TAD $( \pm$ HAM $)$ & 1 & Yes \\
\hline
\end{tabular}

ATRA all-trans retinoic acid, Ida idarubicin, ara-C cytosine arabinoside, $A D$ ara-C daunorubicin, TAD 6-thioguanine ara-C daunorubicin, $H A M$ high-dose ara-C mitoxantrone 
Table 4 Outcome in elderly APL patients with ATRA and chemotherapy

\begin{tabular}{|c|c|c|c|c|c|c|c|c|}
\hline Author (year) [reference] & Number of patients & CR $(\%)$ & $\mathrm{ED}(\%)$ & OS $(\%)$ & EFS $(\%)$ & DFS $(\%)$ & CIR (\%) & Years \\
\hline Mandelli (2003) [31] & 134 & 86 & 12 & 56 & - & 59 & - & - \\
\hline Sanz (2004) [32] & 104 & 84 & 15 & - & - & 79 & 9 & 6 \\
\hline Ades (2005) [33] & 129 & 86 & 14 & 58 & 53 & - & 16 & 4 \\
\hline Lataglia (2011) [34] & 60 & 90 & 10 & 69 & - & 65 & 27 & 5 \\
\hline Ono $(2012[35])$ & 46 & 89 & 11 & 63 & - & 65 & 15 & 10 \\
\hline Lengfelder (2013) [23] & 56 & 82 & 18 & 45 & 40 & 48 & 24 & 7 \\
\hline
\end{tabular}

$C R$ complete remission, $E D$ early death, $O S$ overall survival, $E F S$ event-free survival, $D F S$ disease-free survival, $C I R$ cumulative incidence of relapse

regimens. Therefore, a comparison of the study results is problematic. Nevertheless, some conclusions are possible.

In elderly patients treated in these studies, the $\mathrm{CR}$ rate was lower ( 82 to $90 \%$ ) and the ED rate higher (11 to $18 \%$ ) (Table 4) compared to results of younger study patients mostly reaching CR rates between 90 and $95 \%[6,24]$. This may, in part, be explained by the worse tolerance of chemotherapy-related side effects by older patients. Other factors with negative impact on the ED rate are high initial WBC count and very advanced age. In the study of the German AMLCG including $32 \%$ elderly patients with initial WBC count above $10,000 / \mu 1$, the ED rate in patients with WBC counts below and above 10,000/ $\mu$ l was 8 and $39 \%$, respectively $(p=0.009)$ [23]. Notably, in patients with high WBC counts aged between 60 and 69 years, the ED rate was $25 \%$, and in patients 70 years or older, it was $67 \%$.

It is an important goal in APL treatment to avoid death in CR, particularly due to toxicity of frontline therapy, as relapsed patients have an excellent chance to be cured with salvage regimens [40-42]. The rates of death in CR, which may be in part related to the vulnerability against the chemotherapy, were uniformly higher in elderly patients when compared to younger age groups [23, 31-35]. According to results of the updated French/European APL 93 study, the rate of death in CR was $19 \%$ in patients over 60 years as compared to $6 \%$ in patients aged 18 to 60 years $(p=0.05)$ [43]. The German AMLCG reported a rate of death in CR of $24 \%$ at 10 years in patients over 60 years. In approximately half of these patients, the chemotherapy-related toxicity had influence on the fatal outcome [23]. In an amended Italian ATRA and idarubicin (AIDA) protocol for elderly patients, the second and third consolidation cycle of the original protocol was omitted, and intermittent ATRA maintenance was given to all patients. Compared to the original protocol, the rate of death in CR was reduced from 13 to $8 \%[31,34]$. In the Japanese study, in which a relatively dose-intensive regimen was administered, 5 of 36 elderly patients $(13 \%)$ died before or during consolidation therapy [35]. The Spanish PETHEMA reported 4 deaths among 86 elderly patients (5\%) during consolidation therapy [32].
Long-term remission and probable cure was achieved in more than $50 \%$ of the elderly patients [23, 31-35]. The rates of overall survival (OS), disease-free survival (DFS), and the cumulative incidence of relapse (CIR) of studies are shown in Table 4. The probability of relapse seems to be influenced by the intensity of the chemotherapy and by the risk profile of the patients. Detailed results of the amended AIDA protocol with reduced chemotherapy showed a moderate increase of the CIR of $27 \%$ compared to $23 \%$ of the historical original protocol, but an improved OS of 76 versus $56 \%$, respectively [34]. The German AMLCG reported a significantly inferior 7-year OS and CIR of 26 and $58 \%$ in patients with initial WBC counts over $10,000 / \mu \mathrm{l}$ compared to 55 and $13 \%$, respectively, in patients with lower WBC counts. In 14 selected patients who received treatment intensification with a second induction cycle consisting of age-adapted high-dose ara- $\mathrm{C}$ and mitoxantrone (HAM), the DFS was $83 \%$ [23]. Very longterm results of the updated ALP 93 study showed a 10-year OS survival of $77 \%$ of the whole study population compared to $58 \%$ of the elderly group (range of WBC counts, 900 to $1,900 / \mu \mathrm{l})[43]$.

\section{ATRA and chemotherapy-based treatment in patients with advanced age over 70 years}

There are only few reports on elderly APL patients of advanced age over 70 years. In the report of the APL 93 study, results of 34 (6\%) patients over 70 years were included. Even in these patients, a CR rate of $85 \%$ was achieved [33]. The German AMLCG registered 33 patients over 70 years among 91 patients aged 60 years or older. Of 56 patients treated with 6-thioguanine, ara-C, and daunorubicin (TAD) \pm HAM, 18 patients $(32 \%)$ were older than 70 years. The $\mathrm{CR}$ rate was $89 \%$ in the age group between 60 to 69 years compared to $67 \%$ in patients 70 years or older $(p=0.06)$. The 7 -year OS was 54 versus $25 \%$, respectively $(p=0.048)$, but DFS and CIR showed no difference [23]. 
From 1999 to 2006, 297 patients aged over 70 years with newly diagnosed AML were seen at a single Canadian center. Among these were 13 patients (4\%) with APL. Their median age was 78 years. Three patients $(23 \%)$ had highrisk APL according to the Sanz score. The therapy consisted of ATRA in combination with daunorubicin and ara-C. In patients with impaired left ventricular function, daunorubicin was replaced by amsacrine. The CR rate was $92 \%$, and the 2-year OS and DFS were 76 and $59 \%$, respectively [44].

In an Italian multicenter experience, results of 34 patients over 60 years were reported. The median age was 70 years. Twenty-one percent had high risk according to the Sanz score. Twenty-three patients $(68 \%)$ received treatment according to the GIMEMA AIDA protocol, and $11(32 \%)$ had a personalized approach because of bad performance status or cardiomyopathy. In patients treated according to the protocol, the $\mathrm{CR}$ rate was $74 \%$, and in the non-eligible patients, it was $54 \%$. Ten of 11 patients with ED died from cerebral hemorrhage. The median OS was 38 months [45].

In sporadic elderly patients up to 85 years not qualifying for chemotherapy, ATRA without or combined with lowdose chemotherapy was able to induce remission lasting longer than 3 years. ATRA combined with hydroxyurea for control of leukocytosis is therefore still an option for patients with contraindications against chemotherapy or arsenic trioxide (ATO) [34, 46].

\section{Treatment based on ATO or gemtuzumab ozogamicin in frontline therapy or relapse}

ATO is the most active single agent in treatment of APL. The drug is considerably less toxic compared to approaches with conventional chemotherapy. In particular, treatmentrelated cytopenia is reduced and cardiotoxicity of anthracyclines can be avoided [40]. The most frequently administered ATO dose was $0.015 \mu \mathrm{g} / \mathrm{kg} / \mathrm{day}$, but lower doses were reported to be effective as well [47]. The combination with ATRA was shown to increase the antileukemic efficacy leading to a faster and more extensive reduction of the leukemic clone compared to ATO alone [48]. In most studies reporting results of ATO in frontline therapy, only small numbers of elderly patients have been included.

Recently, a Chinese group presented the results of 33 elderly patients with newly diagnosed APL aged between 60 and 79 years (median age, 65 years) treated with ATO monotherapy for induction of remission followed by postremission therapy with intermittent ATO over 4 years. Eighty-five percent had low/intermediate and $15 \%$ had high risk according to the Sanz score. The rate of hematological CR separated into low, intermediate, and high risk was 100 , 86 , and $80 \%$, respectively. Three patients died from ED due to hemorrhage. Side effects (CTC grade 3/4), probably related to ATO, were very low. OS, DFS, and causespecific survival (time from the first day of ATO therapy to death attributed to APL disease or ATO treatment) were 69,65 , and $85 \%$, respectively [49]. Very recently, an 86year-old Chinese patient with newly diagnosed APL was reported, who entered molecular remission after 60 days of treatment with low-dose ATO $(0.05 \mathrm{mg} / \mathrm{kg} /$ day $)$ followed by low-dose ATRA (15 mg/m²/day [50]).

In relapsed APL, a number of smaller studies with ATO with or without ATRA were reported. Many studies included elderly patients but did not separately report age-related results [42]. In the US pivotal multicenter study, which included the highest number of patients reported so far, 8 of 40 patients were 60 years or older. Six $(75 \%)$ of the older patients and 28 of $32(88 \%)$ younger patients achieved CR. The 18-month OS of the older patients was $38 \%$ compared to $73 \%$ in patients aged from 18 to 59 years [51]. The different outcome may be influenced by the subsequent stem cell transplantation, which is usually restricted to younger age [52]. According to a historical comparison of French patients with relapsed APL, remission induction with ATO was less toxic compared to conventional therapy with ATRA and chemotherapy, and led to an improved feasibility of transplantation and to a reduction of the transplant-related mortality $[40,53]$. Among nine patients from Italy with molecular or hematologic relapse of APL, three were older than 60 years. Eight patients had low/intermediate and one patient had high risk according to the Sanz score. All patients entered molecular remission lasting from 10 months to over 50 months after ATO plus ATRA [54].

Gemtuzumab ozogamicin (GO) is a humanized $\operatorname{IgG}_{4}$ anti-CD33 antibody conjugated with calicheamicin, a stable derivative of a natural tumor antibiotic. The unconjugated antibody is relatively untoxic and primarily facilitates the uptake of the calicheamicin derivative into CD33-positive cells. Intracellularly, calicheamicin initiates single- or double-strand DNA breaks, similar to anthracyclines, finally leading to apoptosis and cell death. APL cells have a strong expression of CD33 and are therefore suitable targets for anti-CD33 antibodies including GO [55]. APL cells are further characterized by a low expression of P-glycoprotein (P-170), probably responsible for the particularly high sensitivity to anthracyclines [56, 57].

The clinical efficacy of GO in APL was shown in several reports. In patients with first to fourth molecular relapse after frontline therapy with the AIDA regimen, GO induced remission in $9(91 \%)$ out of 11 patients tested after two doses of $6 \mathrm{mg} / \mathrm{m}^{2}$ and in $13(100 \%)$ of 13 patients tested after the third dose. The duration of remission was between 3 and over 31 months. GO was administered again in two patients with molecular relapse, and both obtained a new 
molecular remission [58]. In newly diagnosed APL of younger patients, GO added to the effectiveness of ATRA and could replace anthracyclines in the curative backbone of treatment [59]. Some frail elderly patients were reported, who entered molecular remission after ATRA and GO frontline therapy, even with reduced dose of GO [34, 60, 61].

\section{Conclusions}

Elderly APL patients seem to be as sensitive to therapy as younger patients and should be treated with the intention to reach stabilization or cure, if possible. More than $50 \%$ of patients aged over 60 years included in trials can probably be cured with conventional ATRA and anthracycline-based therapy. Even very elderly or frail patients with contraindication against the common standard therapy have a chance to reach long-term remission or cure with less toxic approaches basing on ATO with or without ATRA or, if applicable, combined with reduced chemotherapy or GO, or even with ATRA alone.

The comparison of registry and study data indicates that the study patients represent a positive selection. Older patients with high initial WBC counts and advanced age have a very high risk and may therefore influence the results of clinical trials negatively due to a higher rate of ED or death in remission. Divergent study results in older age may therefore not only be caused by differences of the treatment regimens but also by the risk profile of the patients. Less intensive chemotherapy has the advantage of a lower rate of treatment-associated mortality and the disadvantage of a higher rate of relapse. Intensive treatment regimens are associated with high antileukemic efficacy but are restricted to selected patients.

Hence, new less toxic approaches with broader applicability are needed to improve the prognosis of the older APL patients. The published data with ATO in elderly patients are limited. A recent Italian-German study randomly compared ATRA and ATO with ATRA and chemotherapy in frontline therapy of low/intermediate-risk patients [62]. The superior outcome of patients assigned to the ATO-plus-ATRA arm and the lower toxicity of this therapy indicate that older patients probably represent a particular target group for ATO-based approaches. This should be investigated in larger clinical trials.

Conflict of interest Eva Lengfelder was consultant for Cephalon/Teva and has received research funding. Wolf-Karsten Hofmann and Florian Nolte have no conflict of interest to disclose.

Open Access This article is distributed under the terms of the Creative Commons Attribution License which permits any use, distribution, and reproduction in any medium, provided the original author(s) and the source are credited.

\section{References}

1. WHO (2008) WHO classification of tumours of haemopoietic and lymphoid tissues. WHO Press, Lyon, pp 112-114

2. Rowley JD, Golomb H, Dougherty C (1977) 15/17 Translocation, a consistent chromosomal change in acute promyelocytic leukemia. Lancet 1:549-550

3. De The H, Chomienne C, Lanotte M, Degos L, Dejean A (1990) The $t(15 ; 17)$ translocation of acute promyelocytic leukemia fuses the retinoic acid receptor $\alpha$ gene to a novel transcribed locus. Nature 347:588-561

4. Kakizuka A, Miller WH, Umesono K, Warrell RP, Frankel SR, Murty VV, Dimitrovky E, Evans RM (1991) Chromosomal translocation $\mathrm{t}(15 ; 17)$ in human acute promyelocytic leukemia fuses RAR alpha with a novel putative transcription factor, PML. Cell 66:663-674

5. Alcalay M, Zangrilli D, Fagioli M, Pandolfi PP, Mencarelli A, Lo Coco F, Biondi A, Grigniani F, Pellici PG (1992) Expression pattern of the RAR alpha-PML fusion gene in acute promyelocytic leukemia. Proc Natl Acad Sci USA 89:4840-4844

6. Lengfelder E, Saussele S, Weisser A, Büchner T, Hehlmann R (2005) Treatment concepts of acute promyelocytic leukemia. Crit Rev Oncol Hematol 56:261-274

7. Tallman MS, Kwaan HC (1992) Reassessing the hemostatic disorder associated with acute promyelocytic leukemia. Blood 79:543-553

8. Yanada M, Matsushita T, Asou N, Kishimoto Y, Tsuzuki M, Maeda Y et al (2007) Severe hemorrhagic complications during remission induction therapy for acute promyelocytic leukemia: incidence, risk factors and influence on outcome. Eur J Haematol 78:213-219

9. Sanz MA, Lo-Coco F, Martin G, Avvisati G, Rayón C, Barbui T et al (2000) Definition of relapse risk and role of non-anthracycline drugs for consolidation in patients with acute promyelocytic leukemia: a joint study of the PETHEMA and GIMEMA cooperative groups. Blood 96:1247-1252

10. De la Serna J, Montesinos P, Vellenga E, Rayón C, Parody R, León A et al (2008) Causes and prognostic factors of remission induction failure in patients with acute promyelocytic leukemia treated with all-trans retinoic acid and idarubicin. Blood 111:3395-3402

11. Sanz MA, Martín G, González M, León A, Rayón C, Rivas C et al (2004) Risk-adapted treatment of acute promyelocytic leukemia with all-trans-retinoic acid and anthracycline monochemotherapy: a multicenter study by the PETHEMA group. Blood 103:1237-1243

12. Gale RE, Hills R, Pizzey AR, Kottaridis PD, Swirsky D, Gilkes AF et al (2005) Relationship between FLT3 mutation status, biologic characteristics, and response to targeted therapy in acute ptomyelocytic leukemia. Blood 106:3768-3776

13. Montesinos P, Rayón C, Vellenga E, Brunet S, González J, González $M$ et al (2011) Clinical significance of CD56 expression in patients with acute promyelocytic leukemia treated with all-trans retinoic acid and anthracycline-based regimens. Blood 117:1799-1805

14. Schnittger S, Bacher U, Haferlach C, Kern W, Alpermann T, Haferlach T (2011) Clinical impact of FLT3 mutation load in acute promyelocytic leukemia with $\mathrm{t}(15 ; 17) /$ PML-RARA. Haematologica 96:1799-1807

15. Kanamaru A, Takemoto Y, Tanimoto M, Murakami H, Asou N, Kobayashi T et al (1995) All-trans retinoic acid for the treatment of newly diagnosed acute promyelocytic leukemia. Japan Adult Leukemia Study Group. Blood 85:1202-1206

16. Burnett AK, Grimwade D, Solomon E, Wheatley K, Goldstone A (1999) Presenting white blood cell counts and kinetics of molecular remission predict prognosis in acute promyelocytic leukemia treated with all-trans retinoic acid: results of the randomized MRC trial. Blood 93:4131-4143 
17. Mandelli F, Diviero D, Avvisati G, Luciano A, Barbui T, Bernasconi $C$ et al (1997) Molecular remission in PML/RAR $\alpha$-positive acute promyelocytic leukemia by combined all-trans retinoic acid and idarubicin (AIDA) therapy. Blood 90:1014-1021

18. Tallman MS, Andersen JW, Schiffer CA, Appelbaum FR, Feusner $\mathrm{JH}$, Woods WG et al (2002) All-trans retinoic acid in acute promyelocytic leukemia: long-term outcome and prognostic factor analysis from the North American Intergroup protocol. Blood 100:4298-4302

19. Fenaux P, Chastang C, Chevret S, Sanz M, Dombret H, Archimbaud E et al (1999) A randomized comparison of all transretinoic acid (ATRA) followed by chemotherapy and ATRA plus chemotherapy and the role of maintenance therapy in newly diagnosed acute promyelocytic leukemia. The European APL Group. Blood 94:1192-1200

20. Sanz MA, Montesinos P, Rayón C, Holowiecka A, de la Serna J, Milone $\mathrm{G}$ et al (2010) Risk-adapted treatment of acute promyelocytic leukemia based on all-trans retinoic acid and anthracycline with addition of cytarabine in consolidation therapy for high-risk patients: further improvements in treatment outcome. Blood 115:5137-5146

21. Burnett AK, Hills RK, Grimwade D, Jovanovic JV, Craig J, McMullin MF, Kell J, Wheatley K, Yin JA, Hunter A, Milligan D, Russell NH (2013) Inclusion of chemotherapy in addition to anthracycline in the treatment of acute promyelocytic leukaemia does not improve outcomes: results of the MRC AML15 Trial. Leukemia 27:843-851

22. Lengfelder E, Haferlach C, Saussele S, Haferlach T, Schultheis B, Schnittger $\mathrm{S}$ et al (2009) High dose ara-C in the treatment of newly diagnosed acute promyelocytic leukemia: long-term results of the German AMLCG. Leukemia 23:2248-2258

23. Lengfelder E, Hanfstein B, Haferlach C, Braess J, Krug U, Spiekermann K et al (2013) Outcome of elderly patients with acute promyelocytic leukemia: results of the German Acute Myeloid Leukemia Cooperative Group. Ann Hematol 92:41-52

24. Sanz MA, Grimwade D, Tallman MS, Lowenberg B, Fenaux P, Estey EH, Naoe T, Lengfelder E, Büchner T, Döhner H, Burnett AK, Lo-Coco F (2009) Management of acute promyelocytic leukemia: Recommendations from an expert panel on behalf of the European Leukemia Net. Blood 113:1875-1891

25. Wang ZY, Chen Z (2008) Acute promyelocytic leukemia: from highly fatal to highly curable. Blood 111:2505-2515

26. Vickers M, Jackson G, Taylor P (2000) The incidence of acute promyelocytic leukemia appears constant over most of a human lifespan, implying only one rate limiting mutation. Leukemia 14:722-726

27. Lehmann S, Ravn A, Carlsson L, Antunovic P, Deneberg S, Möllgård L, Derolf AR, Stockelberg D, Tidefelt U, Wahlin A, Wennström L, Höglund M, Juliusson G (2011) Continuing high early death rate in acute promyelocytic leukemia: a populationbased report from the Swedish Adult Acute Leukemia Registry. Leukemia 25:1128-1134

28. Park JH, Qiao B, Panageas KS, Schymura MJ, Jurcic JG, Rosenblat TL, Altman JK, Douer D, Rowe JM, Tallman MS (2011) Early death in acute promyelocytic leukemia remains high despite all-trans retinoic acid. Blood 118:1248-1254

29. Chen Y, Kantarjian H, Wang H, Cortes J, Ravandi F (2012) Acute promyelocytic leukemia. a population-based study on incidence and survival in the United States, 1975-2008. Cancer 118:5811-5818

30. Dores GM, Devesa SS, Curtis RE, Linet MS, Morton LM (2012) Acute leukemia incidence and patient survival among children and adults in the United States, 2001-2007. Blood 119:34-43

31. Mandelli F, Latagliata R, Avvisati G, Fazi P, Rodeghiero F, Leoni F et al (2003) Treatment of elderly patients ( $\geq 60$ years) with newly diagnosed acute promyelocytic leukemia. Results of the Italian multicenter group GIMEMA with ATRA and idarubicin (AIDA) protocols. Leukemia 17:1085-1090
32. Sanz MA, Vellenga E, Rayón C, Díaz-Mediavilla J, Rivas C, Amutio E et al (2004) All-trans retinoic acid and anthracycline monochemotherapy for the treatment of elderly patients with acute promyelocytic leukemia. Blood 104:3490-3493

33. Ades L, Chevret S, De Botton S, Thomas X, Dombret H, Beve B et al (2005) Outcome of acute promyelocytic leukemia treated with all-trans-retinoic acid and chemotherapy in elderly patients: the European group experience. Leukemia 19:230-233

34. Lataglia R, Breccia M, Fazi P, Vignetti M, Di Raimondo F, Sborgia $M$ et al (2011) GIMEMA AIDA 0493 amended protocol for elderly patients with acute promyelocytic leukaemia. Long-term results and prognostic factors. Br J Haematol 154:564-568

35. Ono T, Takeshita A, Kishimoto Y, Kiyoi H, Okada M, Yamauchi $\mathrm{T}$ et al (2012) Long-term outcome and prognostic factors of elderly patients with acute promyelocytic leukemia. Cancer Sci 103:1974-1978

36. McClellan JS, Kohrt HE, Coutre S, Gotlib JR, Majeti R, Alizadeh AA, Medeiros BC (2012) Treatment advances have not improved the early death rate in acute promyelocytic leukemia. Haematologica 97:133-136

37. Degos L, Dombret H, Chomienne C, Daniel MT, Micléa JM, Chastang C, Castaigne S, Fenaux P (1995) All-trans retinoic acid as a differentiating agent in the treatment of acute promyelocytic leukemia. Blood 85:2643-2653

38. Head D, Kenneth JK, Weick J, Files JC, Ryan D, Foucar K, Montiel M, Bickers J, Fishleder A, Miller M et al (1995) Effect of aggressive daunomycin therapy on survival in acute promyelocytic leukemia. Blood 86:1717-1728

39. Kantarjian HM, Keating MJ, Walters RS, Smith TL, McCredie K, Freireich EJ (1987) Role of maintenance chemotherapy in acute promyelocytic leukemia. Cancer 59:1258-1263

40. Thomas X, Pigneux A, Raffoux E, Huguet F, Caillot D, Fenaux P (2006) Superiority of an arsenic trioxide-based regimen over a historic control combining all-trans retinoic acid plus intensive chemotherapy in the treatment of relapsed acute promyelocytic leukemia. Haematologica 91:996-997

41. Sanz MA, Labopin M, Gorin NC, de la Rubia J, Arcese W, Meloni G et al (2007) Hemotopoietic stem cell transplantation for adults with acute promyelocytic leukemia in the ATRA era: a survey of the European Cooperative Group for Blood and Marrow Transplantation. Bone Marrow Transplant 39:461-469

42. Lengfelder E, Hofmann WK, Nowak D (2012) Impact of arsenic trioxide in the treatment of acute promyelocytic leukemia. Leukemia 26:433-442

43. Adès L, Guerci A, Raffoux E, Sanz M, Chevallier P, Lapusan $S$ et al (2010) Very long-term outcome of acute promyelocytic leukemia after treatment with all-trans retinoic acid and chemotherapy: the European APL Group experience. Blood 115:16901696

44. Disperati P, Minden MD, Gupta V, Schimmer AD, Schuh AC, Yee KW, Kamel-Reid S, Chang H, Xu W, Brandwein JM (2007) Acute promyelocytic leukemia in patients aged 70 years and over-a single center experience of unselected patients. Leuk Lymphoma 48:1654-1658

45. Ferrara F, Finizio O, D’Arco A, Mastrullo L, Cantore N, Musto P (2010) Acute promyelocytic leukemia in patients aged over 60 years: multicenter experience of 34 consecutive unselected patients. Anticancer Res 30:967-972

46. Sham RL, Tallman MS (2004) Treatment of acute promyelocytic leukemia in the very elderly: case report and review of the literature. Leuk Res 28:1347-1350

47. Shen Y, Shen ZX, Yan H, Chen J, Zeng XY, Li JM et al (2001) Studies on the clinical efficacy and pharmacokinetics of low-dose arsenic trioxide in the treatment of relapsed acute promyelocytic leukemia: a comparison with conventional dosage. Leukemia 15:735-741 
48. Shen ZX, Shi ZZ, Fang J, Gu BW, Li JM, Zhu YM et al (2004) All-trans retinoic acid/As2O3 combination yields a high quality remission and survival in newly diagnosed acute promyelocytic leukemia. Proc Natl Acad Sci U S A 101:5328-5335

49. Zhang Y, Zhang Z, Li J, Li L, Han X, Han L et al (2012) Longterm efficacy and safety of arsenic trioxide for first-line treatment of elderly patients with newly diagnosed acute promyelocytic leukemia. Cancer 119:115-125

50. Lin J, Zhu H, Li S, Fan H, Lu X (2013) Complete remission of acute promyelocytic leukemia in a very elderly patient after treatment with low dose arsenic and sequential retinoic acid: a case report. Ann Hematol (in press)

51. Soignet SL, Frankel SR, Douer D, Tallman M, Kantarjian H, Calleja E et al (2001) United States multicenter study of arsenic trioxide in relapsed acute promyelocytic leukemia. J Clin Oncol 19:3852-3860

52. Douer D, Hu W, Giralt S, Lill M, DiPersio J (2003) Arsenic trioxide (trisenox) therapy for acute promyelocytic leukemia in the setting of hematopoietic stem cell transplantation. Oncologist 8:132-140

53. Thomas X, Dombret H, Cordonnier C, Pigneux A, Gardin C, Guerci A et al (2000) Treatment of relapsing acute promyelocytic leukemia by all-trans retinoic acid therapy followed by timed sequential chemotherapy and stem cell transplantation. Leukemia 14:1006-1013

54. Breccia M, Cicconi L, Minotti C, Latagliata R, Giannì L, LoCoco F (2011) Efficacy of prolonged therapy with combined arsenic trioxide and ATRA for relapse of acute promyelocytic leukemia. Haematologica 96:1390-1391

55. Walter RB, Appelbaum FR, Estey EH, Bernstein ID (2012) Acute myeloid leukemia stem cells and CD33-targeted immunotherapy. Blood 119:6198-6208

56. Michieli M, Damiani D, Ermacora A, Geromin A, Michelutti A, Masolini P, Baccarani M (2000) P-Glycoprotein (PGP), lung resistance-related protein (LRP) and multidrug resistanceassociated protein (MRP) expression in acute promyelocytic leukaemia. Br J Haematol 108:703-709

57. Paietta E, Andersen J, Racevskis J, Gallagher R, Bennett J, Yunis J, Cassileth P, Wiernik PH (1994) Significantly lower Pglycoprotein expression in acute promyelocytic leukemia than in other types of acute myeloid leukemia: immunological, molecular and functional analyses. Leukemia 8:968-973

58. Lo-Coco F, Cimino G, Breccia M, Noguera NI, Diverio D, Finolezzi E et al (2004) Gemtuzumab ozogamicin (Mylotarg) as a single agent for molecularly relapsed acute promyelocytic leukemia. Blood 104:1995-1999

59. Estey E, Garcia-Manero G, Ferrajoli A, Faderl S, Verstovsek S, Jones D et al (2006) Use of all-trans retinoic acid plus arsenic trioxide as an alternative to chemotherapy in untreated acute promyelocytic leukemia. Blood 107:3469-3473

60. Breccia M, Cimino G, Diverio D, Gentilini F, Mandelli F, Lo Coco F (2007) Sustained molecular remission after low dose gemtuzumab-ozogamicin in elderly patients with advanced acute promyelocytic leukemia. Haematologica 92:1273-1274

61. Finizio O, Pezzullo L, Rocco S, Bene L, De Rosa C, Nunziata GR, Mettivier V (2007) Combination of all-trans-retinoic acid and gemtuzumab ozogamicin in an elderly patient with acute promyelocytic leukemia and severe cardiac failure. Acta Haematol 117:188-190

62. Lo-Coco F, Avvisati G, Orlando SM, Ferrara F, Vignetti M, Fazi P et al. (2012) ATRA and arsenic trioxide (ATO) versus ATRA and idarubicin (AIDA) for newly diagnosed, non high-risk acute promyelocytic leukemia (APL): results of the phase III, prospective, randomized, Intergroup APL0406 Study by the ItalianGerman Cooperative Groups Gimema-SAL-AMLSG. Blood ASH Abstract 6 